\title{
Photochemistry in Polymer Solids V. Decay of Benzophenone Phosphorescence in Polystyrene and in Polycarbonate
}

\author{
Kazuyuki HoRIE, Masako TsuKAmOTO, Keiko MORISHITA, \\ and Itaru MiTA \\ Institute of Interdisciplinary Research, Faculty of Engineering, \\ University of Tokyo, 4-6-1 Komaba, Meguro-ku, \\ Tokyo 153, Japan
}

(Received June 15, 1984)

\begin{abstract}
Decay curves and lifetimes of benzophenone phosphorescence in polystyrene and in bisphenol A polycarbonate (BPA-PC) at $80-433 \mathrm{~K}$ significantly reflect change in the molecular motion of matrix polymers such as glass transition, $\beta$-transition, and $\gamma$-transition. The non-singleexponential decay.curves were observed in both polymers at temperatures between $T_{\gamma}$ and $T_{\mathrm{g}}$, and analyzed using the diffusion-controlled rate coefficient with a time dependent transient term for the dynamic quenching process of benzophenone triplet by phenyl or phenylene groups in the matrix polymers. The diffusion coefficients, $D$, of the reacting functional groups in polystyrene and BPA-PC for the wide temperature range below $T_{\mathrm{g}}$ are much larger than that in PMMA in the same temperature range, showing a higher quenching ability of these polymers for the benzophenone triplet.

KEY WORDS Benzophenone / Phosphorescence / Polystyrene / Polycarbonate / Non-Exponential Decay / Molecular Motion / Glass Transition Temperature / $\beta$-Transition Temperature / $\gamma$-Transition Temperature /
\end{abstract}

Measurements of fluorescence and phosphorescence decays provide valuable information on molecular motion, excited energy transfer and migration, and microstructure in polymer solids. In our previous papers, ${ }^{1,2}$ the decay curves of benzophenone phosphorescence in poly(methyl methacrylate) (PMMA) and other acrylic polymers were observed to deviate markedly from the singleexponential type in the temperature range between $T_{\beta}$ (onset of ester side group rotation of the matrix acrylic polymers) and $T_{\mathrm{g}}$ (glass transition temperature), while the phosphorescence decays exponentially for temperatures below $T_{\beta}$ and above $T_{\mathrm{g}}$ for acrylic polymers. The deviation was attributed to the diffusioncontrolled dynamic quenching (endothermic energy transfer) of the benzophenone triplet by side chain ester groups in these polymers. ${ }^{3}$ The intensity independence of the non-single-ex- ponential decay profile of benzophenone phosphorescence in PMMA was ascertained, ${ }^{4}$ indicating the absence of biphotonic triplettriplet annihilation processes under the present experimental conditions. The decay study of benzophenone phosphorescence has been extended to cases in polystyrene and bisphenol $\mathrm{A}$ polycarbonate in the present paper.

The temperature, ${ }^{6,7}$ concentration, ${ }^{8}$ and molecular weight ${ }^{9,10}$ dependences of fluorescence intensity and lifetime as well as temperature dependence ${ }^{11}$ or polarization ${ }^{12,13}$ of phosphorescence, have been studied for various chromophores in polystyrene. The effects of molecular motion ${ }^{6,7,11,12}$ and free volume $\mathrm{e}^{10}$ of the matrix polymer as well as energy transfer to the matrix polymer ${ }^{14}$ have been discussed in some cases, but in other cases polystyrene is regarded as an inert rigid matrix for photophysical processes of the excited chro- 
mophores. The photochemistry of solid poly(oxycarbonyloxy-1,4-phenyleneisopropylidene-1,4-phenylene) (BPA-PC) has been the subject of several investigations ${ }^{15-17}$ because of the occurrence of photo-Fries rearrangement by deep UV light irradiation inspite of its practical importance from the stand point of excellent transparency and high impact strength. The effect of polycarbonate matrix on the photophysical or photochemical process of the molecularly dispersed chromophores has not been reported so far to our knowledge.

The present paper is concerned with the mechanism and kinetics of the non-exponential decay of benzophenone phosphorescence in polystyrene and BPA-PC at $80-433 \mathrm{~K}$, based on the application of a concept of a diffusion-controlled reaction with a timedependent rate coefficient to dynamic quenching in the solid state.

\section{EXPERIMENTAL}

\section{Materials}

Benzophenone and benzoyl peroxide were purified by the recrystallization from ethanol. Styrene was distilled under reduced pressure and stored in a dark refrigerator. A standard sample of BPA-PC $\left(M_{w}=33,800, M_{w} / M_{n}=2.5\right)$ was purchased from Scientific Polymer Product, Inc.

\section{Sample Preparation}

The purge of oxygen is important in the study of triplet lifetimes even in solid matrices. A solution of benzophenone $\left(8.9 \times 10^{-3} \mathrm{M}\right)$ and benzoyl peroxide $\left(1 \times 10^{-3} \mathrm{M}\right)$ in styrene monomer was evacuated by several freezepump-thaw cycles in a high vacuum system, sealed in a cylindrical Pyrex cell with a diameter of $10 \mathrm{~mm}$, then polymerized at $70^{\circ} \mathrm{C}$ for $120 \mathrm{~h}$, and postcured at $120^{\circ} \mathrm{C}$ for $20 \mathrm{~h}$. The resulting rod sample in the sealed cell was used for phosphorescence measurements. In the case of benzophenone in BPA-PC, a BPA-PC film containing $1.5 \%$ benzophenone $(80 \mu \mathrm{m}$ thickness) was prepared by solvent casting on a quartz plate from BPA-PC and benzophenone solution in dichloromethane and was evacuated at room temperature for two days and at $100^{\circ} \mathrm{C}$ for $4 \mathrm{~h}$ before the phosphorescence measurements in vacuum. A solventcast film of polystyrene $\left(M_{n}=9.6 \times 10^{4}\right.$, $\left.M_{w} / M_{n}=1.1\right) \quad$ containing $4.0 \%$ benzophenone was also prepared in a similar manner from tetrahydrofuran solution.

\section{Measurements of Phosphorescence Decay}

A pulsed nitrogen laser (Avco C950B) with a pulse width of $10 \mathrm{~ns}$ as exciting light at $337 \mathrm{~nm}$, a cryostat (Oxford DN704), a monochromator (Jasco CT10), a photomultiplier (HTV R374), a.transient time converter (Riken Denshi TCG8000), and a desk-top computer (YHP 9825T) were used to measure benzophenone phosphorescence decay at $80-433 \mathrm{~K}$. The details of the measurements are given elsewhere. $^{2}$

\section{Measurements of Luminescence Spectra}

The phosphorescence spectra of benzophenone in polystyrene under vacuum was measured at 80 and $293 \mathrm{~K}$ with a Jasco FP-500 type spectrofluorimeter and Oxford DN704 type cryostat.

\section{RESULTS AND DISCUSSION}

Temperature Dependence of the Decay Curves

The phosphorescence spectra of benzophenone in polystyrene excited at $337 \mathrm{~nm}$ are shown in Figure 1. Three peaks at 420, 450, and $480 \mathrm{~nm}$ observed at $80 \mathrm{~K}$ correspond to the vibrational structure of benzophenone phosphorescence. ${ }^{18}$ The emission lifetimes at these wavelengths were $\tau_{0}=4.2 \mathrm{~ms}$ at $80 \mathrm{~K}$. The minor peak at $390 \mathrm{~nm}$ consisted of two components: one with a very short lifetime ( $\tau<10 \mathrm{~ns})$ and phosphorescence with $\tau_{0}=$ $4.2 \mathrm{~ms}$. The phosphorescence of benzophenone in the polystyrene rod sample could be hardly 


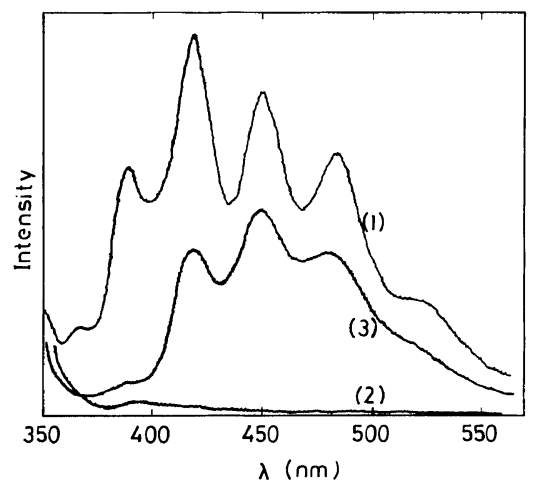

Figure 1. Phosphorescence spectra of benzophenone in polystyrene $\left([\mathrm{BP}]=8.9 \times 10^{-3} \mathrm{M}\right)$ at $-193^{\circ} \mathrm{C}(1)$ and $20^{\circ} \mathrm{C}(2)$, and in PMMA $\left([\mathrm{BP}]=1.7 \times 10^{-3} \mathrm{M}\right)$ at $20^{\circ} \mathrm{C}$ (3). Excitation wavelength is $337 \mathrm{~nm}$.

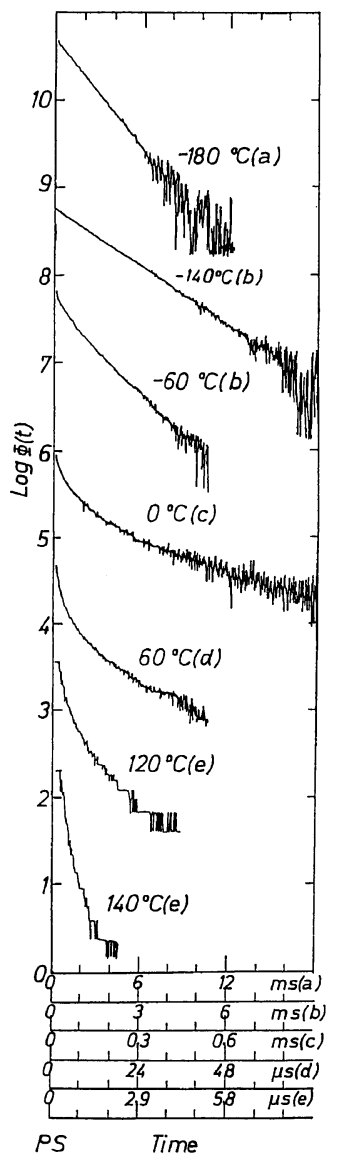

Figure 2. Semilogarithmic decay curves of benzophenone phosphorescence in polystyrene excited by $10 \mathrm{~ns}$ nitrogen laser pulse at $337 \mathrm{~nm}$. Temperature and symbols for the time scales are given beside the curves.

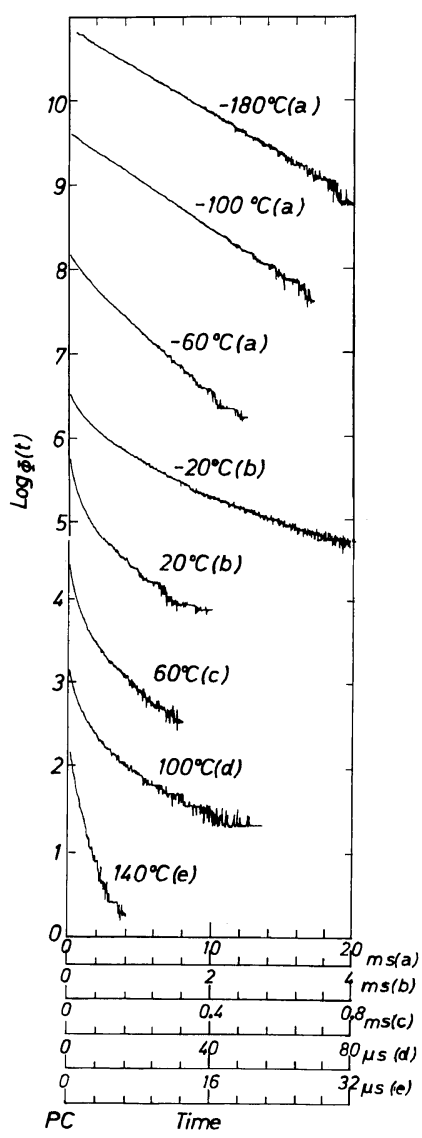

Figure 3. Semilogarithmic decay curves of benzophenone phosphorescence in bisphenol A polycarbonate (BPA-PC) excited by the laser pulse at $337 \mathrm{~nm}$. Temperature and symols for the time scales appear next to the curves.

observed at room temperature with the present spectrofluorimeter, indicating a predominant quenching process for the benzophenone triplet by the polystyrene matrix. The benzophenone phosphorescence was observed in PMMA rod sample even at room temperature, as shown in Figure 1.

Typical decay curves of benzophenone phosphorescence at $450 \mathrm{~nm}$ at various temperatures in polystyrene rod and BPA-PC film samples excited by a 10 -ns nitrogen laser pulse at $337 \mathrm{~nm}$ are shown in Figures 2 and 3, respectively. The same decay profiles with the same lifetimes were observed for polystyrene 
film samples as those for polystyrene rod sample. The phosphorescence intensity, $\Phi(t)$, decreases as a single exponentially at temperatures below the $\gamma$-transition temperature, $T_{\gamma}$, corresponding to phenyl or phenylene group rotation $\left(T_{\gamma} \cong-100^{\circ} \mathrm{C}\right.$ for polystyrene ${ }^{11}$ and also $T_{\gamma} \cong-100^{\circ} \mathrm{C}$ for $\left.\mathrm{BPA}-\mathrm{PC}^{19}\right)$. There was a deviation from single exponential, which became more pronounced with increasing temperature. The regression to the single exponential decay above $T_{\mathrm{g}}$, clearly observed in poly(methyl acrylate) and other methacrylic polymers, ${ }^{1,2}$ was rather ambiguous in the present cases.

The lifetimes of benzophenone phosphorescence due to spontaneous deactivation, $\tau_{0}=1 / k_{0}$, where $k_{0}=k_{\mathrm{PT}}+k_{\mathrm{IT}}$ is the rate constant for spontaneous deactivation consisting of phosphorescence $\left(k_{\mathrm{PT}}\right)$ and non-radiative deactivation $\left(k_{\mathrm{IT}}\right)$ processes, were $4.2 \mathrm{~ms}$ in polystyrene and PBA-PC at $80 \mathrm{~K}$. A small difference in $\tau_{0}$ from those in PMMA and other acrylic polymers $\left(\tau_{0}=5.0 \mathrm{~ms}\right.$ at $80 \mathrm{~K},{ }^{1,2}$ $4.6 \mathrm{~ms}$ at $77 \mathrm{~K}^{20}$ ) was probably due a weak interaction of benzophenone triplet with these aromatic matrices. The $k_{\mathrm{IT}}$ should be negligibly small compared to $k_{\mathrm{PT}}$ in PMMA at $77 \mathrm{~K} .^{20}$ The smaller lifetimes for the phosphorescence of triphenylene and coronene in polystyrene at $77 \mathrm{~K}$ compared to those in PMMA at $77 \mathrm{~K}$ were also observed. ${ }^{14}$

Deviation in the decay curves from the exponential above $T_{\gamma}$ of the matrix polymers suggests a new intermolecular deactivation process for the benzophenone triplet. The quenching of this triplet by a phenyl group was proposed to proceed through an exciplex formation between the excited triplet state of benzophenone and $\pi$-orbital of the phenyl group. ${ }^{21}$ The quenching rate constant of benzophenone triplet by polystyrene in solution was found to be $1.2 \times 10^{6}$ unit- $^{-1} \mathrm{~s}^{-1}$ in benzene $^{22}$ and $4.0 \times 10^{6}$ unit- $^{-1} \mathrm{~s}^{-1}$ in acetonitrile $\mathrm{e}^{23}$ at $30^{\circ} \mathrm{C}$. Thus, the dynamic quenching of benzophenone triplet by the side-chain phenyl group in polystyrene or by the main- chain phenylene group in PBA-PC should cause the deviation in the phosphorescence decay from a single exponential type. It should be noted that the intrinsic (chemical) rate constant, $k$, for the quenching of benzophenone triplet by polystyrene was about $10^{3}$ times that by the ester group in the acrylic $\operatorname{polymers}^{2}\left(k=3.9 \times 10^{3} \mathrm{M}^{-1} \mathrm{~s}^{-1}\right.$ at $\left.30^{\circ} \mathrm{C}\right)$. The possibility of non-exponential decay due to triplet-triplet annihilation can be eliminated in the present cases by the intensity independence of the non-exponential decay profiles.

\section{Kinetic Parameters for Quenching in Poly-} styrene and $B P A-P C$

Kinetics for the non-exponential decay of benzophenone triplet $\left({ }^{3} \mathrm{BP}^{*}\right)$ in polymer solids due to diffusion-controlled dynamic quenching including non-equilibrium $\sqrt{t}$ term have been presented and used to explain the decay profiles of benzophenone phosphorescence in PMMA and other acrylic polymers. ${ }^{3}$ The same kinetic scheme (eq 1 and 2) was applied to the present cases.

$$
\begin{aligned}
& { }^{3} \mathrm{BP}^{*} \stackrel{k_{0}}{\longrightarrow} \mathrm{BP} \\
& { }^{3} \mathrm{BP}^{*}+Q \stackrel{k_{\mathrm{q}}}{\longrightarrow} \mathrm{BP}+Q
\end{aligned}
$$

Here, $Q$ denotes the phenyl group in polystyrene or phenylene group in BPA-PC, and $k_{\mathrm{q}}$, the quenching rate coefficient of benzophenone triplet by the phenyl or phenylene group. Since the diffusion process of a phenyl or phenylene group approaching triplet benzophenone is controlled by the side-chain rotation and local segmental motion of the polymer chains, the bimolecular rate coefficient, $k_{\mathrm{q}}$, is expressed by eq 3 ,

$$
k_{\mathrm{q}}=\frac{4 \pi R D N}{1+4 \pi R D N / k}\left\{1+\frac{R}{(1+4 \pi R D N / k) \sqrt{\pi D t}}\right\}
$$

where $D$ is the sum of the diffusion coefficient for the carbonyl group in benzophenone and that for the phenyl or phenylene group, $R$, the 
reaction radius between the reacting two groups, $k$, the intrinsic (chemical) rate constant, and $N$, the Avogadro number divided by $10^{3}$. When $k_{\mathrm{q}}$ is controlled by the diffusion process of the two groups $(k \gg 4 \pi R D N)$, eq 3 is reduced to eq 4 ,

$k_{\mathrm{q}}=4 \pi R D N(1+R / \sqrt{\pi D t})=A+B / \sqrt{t}$

with

$$
A=4 \pi R D N, \quad B=4 R^{2}(\pi D)^{1 / 2} N
$$

and the rate coefficient $k_{\mathrm{q}}$ includes a timedependent term important at the very early stage of the reaction where the steady-state diffusive flux of the quenching group is not yet attained.

The decay rate of benzophenone triplet is given by eq 5 , and thus,

$$
\begin{aligned}
-\mathrm{d}\left[{ }^{3} \mathrm{BP}^{*}\right] / \mathrm{d} t & =\left(k_{0}+k_{\mathrm{q}}[\mathrm{Q}]\right)\left[{ }^{3} \mathrm{BP} *\right] \\
& =\left(k_{0}+A[\mathrm{Q}]+B[\mathrm{Q}] t^{-1 / 2}\right)\left[{ }^{3} \mathrm{BP}^{*}\right]
\end{aligned}
$$

so that,

$$
\begin{aligned}
{\left[{ }^{3} \mathrm{BP} *\right]=} & {\left[{ }^{3} \mathrm{BP}^{*}\right]_{0} } \\
& \times \exp \left\{-\left(k_{0}+A[\mathrm{Q}]\right) t-2 B[\mathrm{Q}] t^{1 / 2}\right\}
\end{aligned}
$$

for the concentration of benzophenone triplet, $\left[{ }^{3} \mathrm{BP}^{*}\right]$, at time, $t$, where $\left[{ }^{3} \mathrm{BP}^{*}\right]_{0}$ is the initial concentration of benzophenone triplet. The phosphorescence intensity, $\Phi(t)$, is proportional to $k_{\mathrm{PT}}\left[{ }^{3} \mathrm{BP} *\right]$, so we get finally

$$
\begin{aligned}
\ln \Phi(t) & =-\left(k_{0}+A[\mathrm{Q}]\right) t-2 B[\mathrm{Q}] t^{1 / 2} \\
& =-(t / \tau)-C(t / \tau)^{1 / 2}
\end{aligned}
$$

where,

$$
\begin{aligned}
& 1 / \tau=k_{0}+A[\mathrm{Q}]=k_{0}+4 \pi R D N[\mathrm{Q}] \\
& B=C \tau^{-1 / 2} /(2[\mathrm{Q}])=4 R^{2}(\pi D)^{1 / 2} N .
\end{aligned}
$$

The curve fitting for the non-single-exponential phosphorescence decay with eq 7 by the non-linear least-square method calculated with a YHP 9825T desk-top computer gives the values of $\tau$ and $C$, and hence $B$ from eq 9 for each decay curve. A typical curve fitting

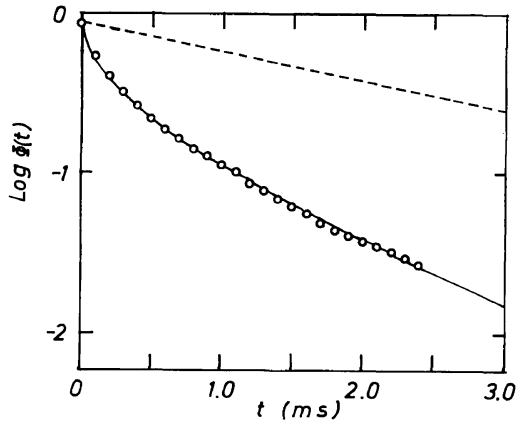

Figure 4. Curve fitting profile of experimental data (O) with eq 7 for benzophenone phosphorescence in BPA-PC at $-20^{\circ} \mathrm{C}$. The solid line is calculated for $-(t / \tau)-C(t / \tau)^{1 / 2}$ using $\tau=2.5 \mathrm{~ms}$ and $C=2.6$, and the dotted line, for $-(t / \tau)$.

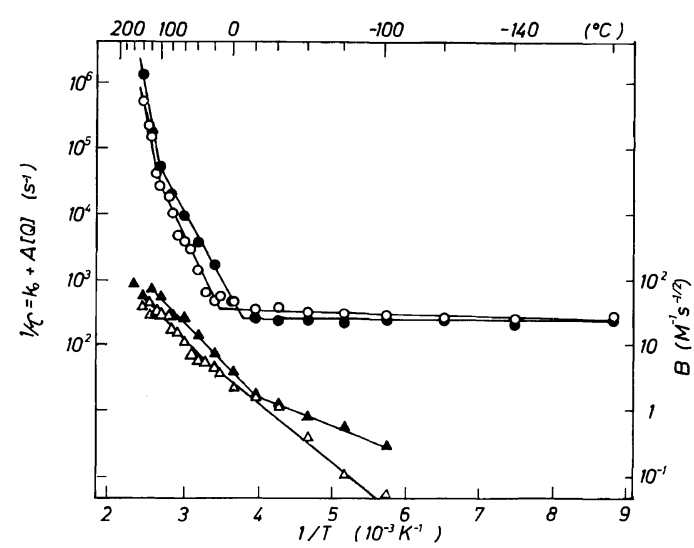

Figure 5. Arrhenius plots of kinetic parameter $1 / \tau$ $(\mathrm{O}, \boldsymbol{O})$ and $\mathrm{B}(\triangle, \boldsymbol{\Delta})$ for the phosphorescence decay of benzophenone in polystyrene $(\boldsymbol{O}, \boldsymbol{\Delta})$ and $\mathrm{BPA}-\mathrm{PC}$ $(\bigcirc, \triangle)$.

profile is shown in Figure 4. The standard deviation was $2-3 \%$ in usual cases, but sometimes several percent at temperatures near $T_{\mathrm{g}}$ of the matrix polymers. The temperature dependence of the parameters, $1 / \tau$ and $B$, calculated using phenyl or phenylene group concentration $[\mathrm{Q}]=10.0 \mathrm{M}$ (polystyrene) and 9.45 M (BPA-PC) is given in Figure 5.

The onset of deviation from single-exponential decay is observed in Figure 5 as the appearance of parameter $B$ at $\gamma$-transition temperature, $T_{\gamma}$, corresponding to the relaxation of the phenyl or phenylene group 
rotation in polystyrene $\mathrm{e}^{11}$ and in BPA-PC. ${ }^{19}$ The nature of the molecular motion concerning the $\gamma$-relaxation of BPA-PC at $-100^{\circ} \mathrm{C}$ is related to the motion of the monomer unit as a whole with a rapid phenylene ring rotation, ${ }^{19}$ though this is still open to discussion. ${ }^{24,25}$ The kinetic parameter, $1 / \tau$, is almost constant over a wide range of the low temperature region by as much as $120-130^{\circ}$ below each $T_{\mathrm{g}}$, and has almost the same value for polystyrene and BPA-PC. This suggests that $4 \pi R D N[\mathrm{Q}] \ll k_{0}$ in eq 8 , so that $1 / \tau \cong k_{0}$ in this temperature range. The lifetime, $\tau_{0}=1 / k_{0}$, of the benzophenone triplet is $4.2 \mathrm{~ms}$ at $80 \mathrm{~K}$ for these polymers. The $\tau_{0}$ was $3.7 \mathrm{~ms}$ in polystyrene and $2.9 \mathrm{~ms}$ in BPA-PC at $-20^{\circ} \mathrm{C}$ due to a slight increase in the non-radiative deactivation $\left(k_{\mathrm{IT}}\right)$. The onset of the increase in $1 / \tau$ suggests that $4 \pi R D N[\mathrm{Q}]$ becomes larger than $k_{0}$ in a higher temperature range. The approximation of

$$
1 / \tau \cong 4 \pi R D N[\mathrm{Q}] \quad \text { for } T>T_{\mathrm{g}}-120^{\circ}
$$

is supported by the fact that the activation energies, $E$, for $1 / \tau\left(41-46 \mathrm{~kJ} \mathrm{~mol}^{-1}\right)$ are almost twice as large as $E$ for $B(20-22 \mathrm{~kJ}$ $\mathrm{mol}^{-1}$ ) in the temperature range of $T_{\mathrm{g}}$ $120^{\circ}<T<T_{\mathrm{g}}$. The glass transition temperature, $T_{\mathrm{g}}$, was well observed as a break at $100^{\circ} \mathrm{C}$ in the Arrhenius plot of $1 / \tau$ of polystyrene (Figure 5) due to change in the temperature dependence of $D$ from below to above $T_{\mathrm{g}}$. In the case of BPA-PC, measurements at several points for $T>T_{\mathrm{g}}$ were difficult due to the very rapid decay of benzophenone phospho- rescence, but the Arrhenius plot of the lifetime of pyrene phosphorescence in $\mathrm{PBA}-\mathrm{PC}^{26}$ showed a marked break at $150^{\circ} \mathrm{C}$ corresponding to the $T_{\mathrm{g}}$ of BPA-PC. ${ }^{19}$ Other breaks observed at $-20^{\circ} \mathrm{C}$ for $B$ of polystyrene and at 100 and $20^{\circ} \mathrm{C}$ for $1 / \tau$ and $B$ of BPA-PC in Figure 5 would correspond to the $\beta$-transition temperatures due to the local mode relaxation of the main chain. ${ }^{27}$ The $\beta$-relaxation in polycarbonate has been explained by packing defects in the glassy state $^{19}$ or by local chainbackbone motion depending widely on annealing and/or drawing conditions of the sample. ${ }^{28}$ Thus, it should be noted that benzophenone and other phosphorescent chromophores can act as new molecular probes for detecting the sub-glass transitions of polycarbonate and other polymers which changed considerably by annealing and/or drawing of the samples. A preliminary result in the case of benzophenone in PMMA was shown previously. ${ }^{1}$ The crossover of $k_{\mathrm{q}}$ from the diffusion-controlled to an activation-controlled value observed in the case of poly(methyl acrylate) ${ }^{3}$ was not noted in the present cases because of the much larger intrinsic rate constant, $k$, for quenching by the phenyl or phenylene group than $k$ for quenching by the ester group. The values of $T_{\mathrm{g}}, T_{\beta}$, and $T_{\gamma}$ for these polymers are summarized in Table I.

$$
\begin{aligned}
& \text { A combination of eq } 9 \text { and } 10 \text { gives } \\
& \qquad C=4 R^{3 / 2} N^{1 / 2}[\mathrm{Q}]^{1 / 2}
\end{aligned}
$$

suggesting $C$ to be constant for $T>T_{\mathrm{g}}-120^{\circ}$.

\begin{tabular}{|c|c|c|c|c|c|c|c|c|c|c|}
\hline \multirow[t]{2}{*}{ Polymer } & \multirow{2}{*}{$\frac{T_{\gamma}}{{ }^{\circ} \mathrm{C}}$} & \multirow{2}{*}{$\frac{T_{\beta}}{{ }^{\circ} \mathrm{C}}$} & \multirow{2}{*}{$\frac{T_{\mathrm{g}}}{{ }^{\circ} \mathrm{C}}$} & \multirow{2}{*}{$\frac{R}{\AA}$} & \multirow{2}{*}{$\begin{array}{c}k_{0} \\
\text { at } \\
-193^{\circ} \mathrm{C}-\end{array}$} & \multicolumn{2}{|c|}{$\frac{D}{\mathrm{~cm}^{2} \mathrm{~s}^{-1}}$} & \multicolumn{3}{|c|}{$\frac{E \text { for } D}{\mathrm{~kJ} \mathrm{~mol}^{-1}}$} \\
\hline & & & & & & at $20^{\circ} \mathrm{C}$ & at $T=T_{\mathrm{g}}$ & $T<T_{\beta}$ & $T_{\beta}<T<T_{\mathrm{g}}$ & $T>T_{\mathrm{g}}$ \\
\hline Polystyrene & -100 & -20 & 100 & 5.8 & $2.4 \times 10^{2}$ & $4.6 \times 10^{-13}$ & $1.5 \times 10^{-11}$ & 16 & 40 & 100 \\
\hline BPA-PC & -100 & 20,100 & 150 & 5.2 & $2.4 \times 10^{2}$ & $1.3 \times 10^{-13}$ & $4.0 \times 10^{-10}$ & 30,44 & 100 & \\
\hline $\mathrm{PMMA}^{3}$ & $-40\left(T_{\beta}\right)$ & $40\left(T_{\alpha^{\prime}}\right)$ & 110 & 5.0 & $2.0 \times 10^{2}$ & $5.0 \times 10^{-14}$ & $1.5 \times 10^{-12}$ & $29\left(T<T_{\alpha^{\prime}}\right)$ & $40\left(T_{\alpha^{\prime}}<T<T_{\mathrm{g}}\right)$ & ) 131 \\
\hline
\end{tabular}

Table I. Transition temperatures and kinetic parameters for phosphorescence decays of benzophenone in polymer matrices 


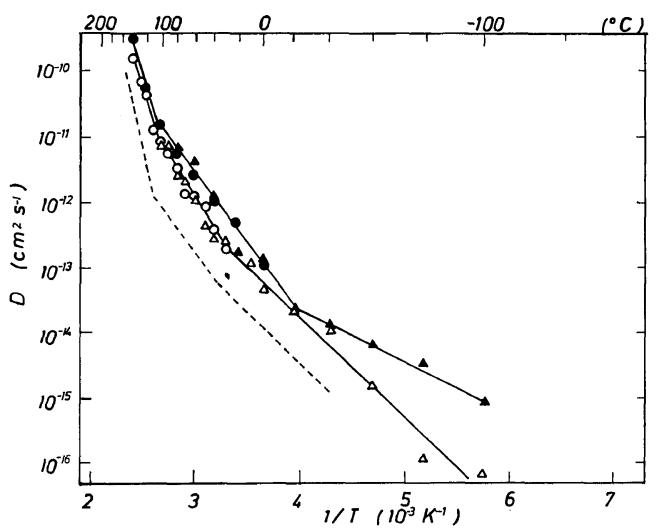

Figure 6. Arrhenius plots of diffusion coefficient, $D$, of interacting groups calculated from $1 / \tau(O, O)$ and $B$ $(\triangle, \boldsymbol{\Delta})$ for dynamic quenching of benzophenone triplet by the phenyl group in polystyrene $(\boldsymbol{O}, \boldsymbol{\Delta})$ and by the phenylene group in BPA-PC $(O, \triangle)$. The value of $D$ for PMMA is shown by the dotted line.

The average reaction radius, $R$, for the quenching of benzophenone triplet by the phenyl or phenylene group was determined from eq 11 to be $5.8 \AA$ for polystyrene and $5.2 \AA$ for BPAPC. The values of 5- $6 \AA$ for the reaction radius between functional groups are reasonable for the triplet quenching through exciplex formation.

The diffusion coefficient, $D$, for the reacting carbonyl group and phenyl or phenylene group was calculated from eq 9 and 10 together with the average value of $R$ given above, and is shown against $1 / T$ in Figure 6 . The breaks corresponding to $T_{\mathrm{g}}$ at $100^{\circ} \mathrm{C}$ and $T_{\beta}$ at $-20^{\circ} \mathrm{C}$ were observed for polystyrene, and two breaks corresponding $T_{\beta}$ at 100 and $20^{\circ} \mathrm{C}$ for $\mathrm{BPA}-\mathrm{PC}$. The temperature dependence of $D$ obtained for the phosphorescence decay of benzophenone in $\mathrm{PMMA}^{3}$ is also shown in Figure 6 by the dotted line. The ten times higher value of $D$ at $20^{\circ} \mathrm{C}$ in polystyrene than in PMMA accounts for the disappearance of the phosphorescence spectra of benzophenone at room temperature in Figure 1 on changing the matrix polymer from PMMA to polystyrene. BPA-PC showed very high $D$ values for the temperature range below $T_{\mathrm{g}}$ compared to those for PMMA at the same temperatures inspite of the higher $T_{\mathrm{g}}$ than that of PMMA. This is another indication of a large free volume density of polycarbonate, ${ }^{29}$ which is consistent with its high impact strength. The values of $D$ and $R$ for these polymers along with the activation energy $E$ for $D$ in each region are listed in Table I. It should be noted that $D$ in the present paper is defined as the translational diffusion coefficient for the reacting functional groups but not for the molecule. The diffusion process at temperatures below $T_{\mathrm{g}}$ probably arises from rotation of the benzophenone molecule and segmental motion within a few monomer units of matrix polymers, but not by the mass diffusion over long distance. Nevertheless it may be said that a comparison of $D$ values for various polymers will provide new clues for estimating the mobility and reactivity of small molecules or groups in polymer matrices.

In conclusion, the non-single-exponential decay curves for benzophenone phosphorescence in polystyrene and BPA-PC for the temperature range of $T_{\gamma}<T<T_{\mathrm{g}}$ were analyzed from the effects of a time-dependent transient term in the diffusion-controlled intermolecular rate coefficient, $k_{\mathrm{q}}$, for the quenching of the benzophenone triplet by phenyl or phenylene group of the matrix polymers. The resulting kinetic parameters such as $1 / \tau, B$, and $D$ well reflect molecular motion, glass transition, and other secondary transitions of the matrix polymers.

Acknowledgement. This work was supported in part by a Grant-in-Aid for Scientific Research (No. 57550561) from the Ministry of Education, Science, and Culture of Japan.

\section{REFERENCES}

1. K. Horie and I. Mita, Chem. Phys. Lett., 93, 61 (1982).

2. K. Horie, K. Morishita, and I. Mita, Kobunshi Ronbunshu, 40, 217 (1983).

3. K. Horie, K. Morishita, and I. Mita, Macro- 
molecules, 17, 1746 (1984).

4. K. Horie and I. Mita, Eur. Polym. J., 20, 1037 (1984).

5. I. M. Fraser, J. R. MacCallum, and K. T. Moran, Eur. Polym. J., 20, 425 (1984).

6. C. W. Frank and L. A. Harrah, J. Chem. Phys., 61, 1526 (1974).

7. H. Itagaki, K. Horie, and I. Mita, Eur. Polym. J., 19, 1201 (1983).

8. G. E. Johnson, Macromolecules, 13, 145, 839 (1980).

9. S. N. Semerak and C. W. Frank, Macromolecules, 14, 443 (1981).

10. R. O. Loutfy, Macromolecules, 16, 678 (1983).

11. A. C. Somersall, E. Dan, and J. E. Guillet, Macromolecules, 7, 233 (1974).

12. L. J. Miller and A. M. North, J. Chem. Soc., Faraday Trans. 2, 71, 1233 (1975).

13. R. D. Burkhart and A. A. Abla, J. Phys. Chem., 86, 468 (1982).

14. A. N. Jassim, J. R. MacCallum, and T. M. Shepherd, Eur. Polym. J., 17, 125 (1981).

15. N. Tsubakiyama, S. Sasaki, S. Hiraki, and C. Kujirai, Kobunshi Ronbunshu, 31, 629 (1974).

16. A. Gupta, A. Rembaum, and J. Moacanin, Macromolecules, 11, 1285 (1978).

17. A. Gupta, R. Liang, J. Moacanin, R. Goldbeck, and D. Kliger, Macromolecules, 13, 262 (1980).
18. M. W. Wolf, K. D. Legg, R. E. Brown, L. A. Singer, and J. H. Parks, J. Am. Chem. Soc., 97, 4490 (1975).

19. A. F. Yee and S. A. Smith, Macromolecules, 14, 54 (1981).

20. W. H. Melhuish, Trans. Faraday Soc., 62, 3384 (1966).

21. M. W. Wolf, R. E. Brown, and L. A. Singer, J. Am. Chem. Soc., 99, 526 (1977).

22. I. Mita, T. Takagi, K. Horie, and Y. Shindo, Macromolecules, 17, 2256 (1984).

23. K. Horie, T. Takagi, I. Mita, Y. Shindo, H. Sato, and Y. Tanaka, Polym. J., 16, 887 (1984).

24. A. A. Jones, J. F. O'Gara, P. T. Inglefield, J. T. Bendler, A. F. Yee, and K. L. Ngai, Macromolecules, 16, 658 (1983).

25. P. Tekely and E. Turska, Polymer, 24, 667 (1983).

26. K. Horie, M. Tsukamoto, and I. Mita, Preprints, 1st SPSJ International Polymer Conference, Kyoto, 1984.

27. G. E. Robert and E. F. T. White, "The Physics of Glassy Polymers," R. H. Haward, Ed., Applied Science Publishers, London, 1973, p 153.

28. M. Kochi, T. Sasaki, and H. Kambe, Polym. J., 10, 169 (1978).

29. B. D. Malhotra and R. A. Pethrick, Eur. Polym. J., 19, 457 (1983). 